\title{
Test of a Magnetic Device for the Amelioration of Scale Formation at Treatment Facility D
}

\author{
P.W. Krauter \\ J.E. Harrar \\ S.P. Orloff \\ S.M. Bahowick
}

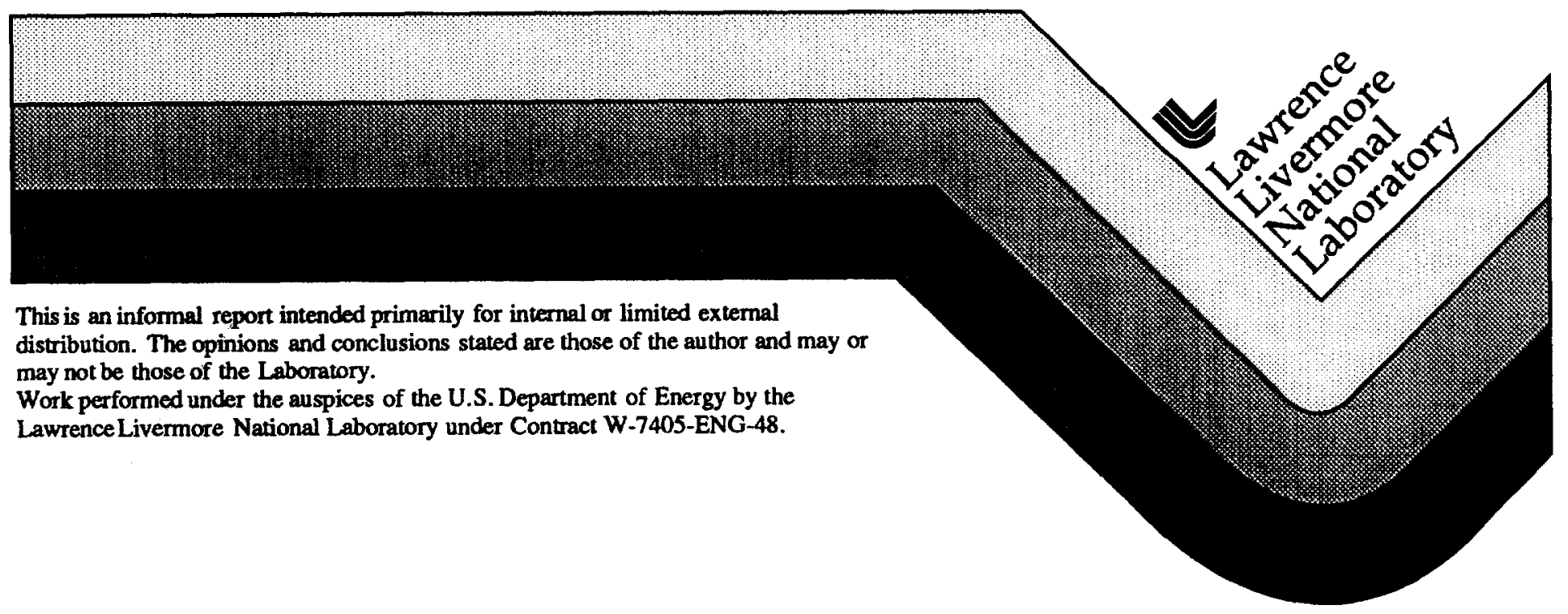




\section{DISCLAIMER}

This document was prepared as an account of work sponsored by an agency of the United States Government. Neither the United States Government nor the University of California nor any of their employees, makes any warranty, express or implied, or assumes any legal liability or responsibility for the accuracy, completeness, or usefulness of any information, apparatus, product, or process disclosed, or represents that its use would not infringe privately owned rights. Reference herein to any specific commercial product, process, or service by trade name, trademark, manufacturer, or otherwise, does not necessarily constitute or imply its endorsement, recommendation, or favoring by the United States Government or the University of California. The views and opinions of authors expressed herein do not necessarily state or reflect those of the United States Government or the University of California, and shall not be used for advertising or product endorsement purposes.

This report has been reproduced directly from the best available copy.

\section{Available to DOE and DOE contractors from the Office of Scientific and Technical Information \\ P.O. Box 62, Oak Ridge, TN 37831}

Prices available from (615) 576-8401, FTS 626-8401

Available to the public from the

National Technical Information Service

U.S. Department of Commerce 5285 Port Royal Rd.

Springfield, VA 22161 


\title{
Test of a Magnetic Device for the Amelioration of Scale Formation at Treatment Facility D
}

\author{
P. W. Krauter, J. E. Harrar, S. P. Orloff, and S. M. Bahowick \\ Environmental Protection Department \\ Lawrence Livermore National Laboratory \\ University of California \\ Livermore, California 94551
}

\begin{abstract}
A commercial device (Descal-A-Matic ${ }^{\circledR}$, Norfolk, VA) designed to treat water by means of a magnetic field has been evaluated for its effect on the formation of calcite scale at LLNL Treatment Facility D. At this facility, volatile organic contaminants (VOCs) are removed by air stripping, which raises the water $\mathrm{pH}$, causing the deposition of calcium carbonate as calcite scale downstream. To evaluate the magnetic treatment technique, the ground water was passed through the Descal-A-Matic ${ }^{\circledR}$ device before treatment by the air stripping unit, and the resulting scale formation and other water characteristics were compared with those found during a test with no water treatment and a test with chemical treatment with a polyphosphate additive. No beneficial effect was found when using the magnetic device.
\end{abstract}

\section{Introduction}

At the Lawrence Livermore National Laboratory (LLNL), ground water is being treated to remove contaminants such as volatile organic compounds and chromium by several types of processes. At Treatment Facility D, remediation of volatile organics is accomplished by sparging the water with air, and the chromium is removed by an ionexchange process. The air stripping has the effect of raising the $\mathrm{pH}$ of the water from $\sim 7$ to $\sim 8$, probably as result of also removing the carbon dioxide from the water. In the absence of further water treatment, calcium carbonate $\left(\mathrm{CaCO}_{3}\right)$ scale deposits on the downstream equipment, which causes operational problems. At present, this scale deposition is being controlled by the addition of a polyphosphate formulation (JP-7, Jaeger Products, Inc., Houston, TX), but the use of this chemical is not completely satisfactory because of stringent discharge limits for the treated water. A more benign method of scale control is highly desirable. Therefore, we evaluated the magnetic technique as a possible alternative.

The effects of magnetic fields on chemical reactions in water, and the use of a magnetic apparatus to retard scale formation in process waters appear to be active fields of investigation and commercialization. In the U.S., there are at least twelve companies that market equipment for water treatment that is based on magnetic and/or electrostatic principles. These devices are apparently successful in controlling scale in many processes, but the exact mechanism is still unknown and the subject of some controversy. Baker and Judd (1996) have recently reviewed this literature, and an 
international conference was held recently on this topic in England (The Economist, 1996; Chem. Eng. News, 1996).

This report describes the results of an evaluation of one such magnetic antiscale device, a unit marketed by the Descal-A-Matic ${ }^{\circledR}$ Company of Norfolk, VA. This particular unit is a flow-through device, in which the water is subjected to a number of alternating north-south magnetic fields. The magnetic fields are said to alter the state of the water in such a manner that the tendency for the formation of scale (in our case, calcium carbonate) from the water is retarded or decreased. To test this apparatus, three tests of 13-18 days duration were carried out: (1) a baseline or control test (LX-116) in which water flowed without any treatment; (2) a test (LX-128) during which the water was dosed with the JP-7 antiscalant, our current antiscale treatment; and (3) a test (LX-122) with the Descal-A-Matic ${ }^{\circledR}$ unit in place.

The progress of each test was monitored by means of several techniques. First, the general behavior of the air-stripping process, as monitored by pressure in the flow system, was noted. Second, weighed test coupons to measure the accumulation of scale were placed in the system at various points. These coupons consisted of sections of stainless-steel screen. Third, the apparent corrosion rates of mild steel at four points in the system were measured by means of the Linear Polarization Resistance (LPR) technique (Mansfeld, 1975). In brief, this technique exploits the fact that corrosion is an electrochemical process. The LPR instrument applies a voltage to a specimen of metal, and an electrolytic current is measured, which is converted to an equivalent, long-term corrosion rate. Because the formation of an impervious scale on the specimens decreases the corrosion rate, the LPR technique is an indirect indicator of the rate of scale formation. The LPR specimens were also weighed before and after the tests to give an additional indication of scaling rates. The mineralogy of the scales that formed in the baseline and magnetic-device tests was examined by $\mathrm{x}$-ray diffraction analysis. The important water chemistry parameters, such as $\mathrm{pH}$, total alkalinity and temperature, were measured periodically at several points in the system during the tests.

\section{Equipment and Experimental Procedures}

Figure 1 is a schematic diagram of the overall system at Treatment Facility D (see the Operations and Maintenance Manual, Groundwater Treatment Facility "D", Building 472 and Adjacent Equipment, Rev. 0, Lawrence Livermore National Laboratory, November, 1995, for additional details and the operating characteristics of this facility). In this facility, water from several wells is pumped into a holding tank, and then into the treatment process. The treatment process is operated for about $8 \mathrm{~h}$ during the daytime, and then shut down overnight while the holding tank is again filled. The scaling tests reported here were conducted while the facility was operated in this manner, i. e., with alternating periods of flow and no-flow with the specimens and coupons remaining in place throughout the test. The LPR and water chemistry measurements were carried out during water flow, near the end of each day's treatment run. 


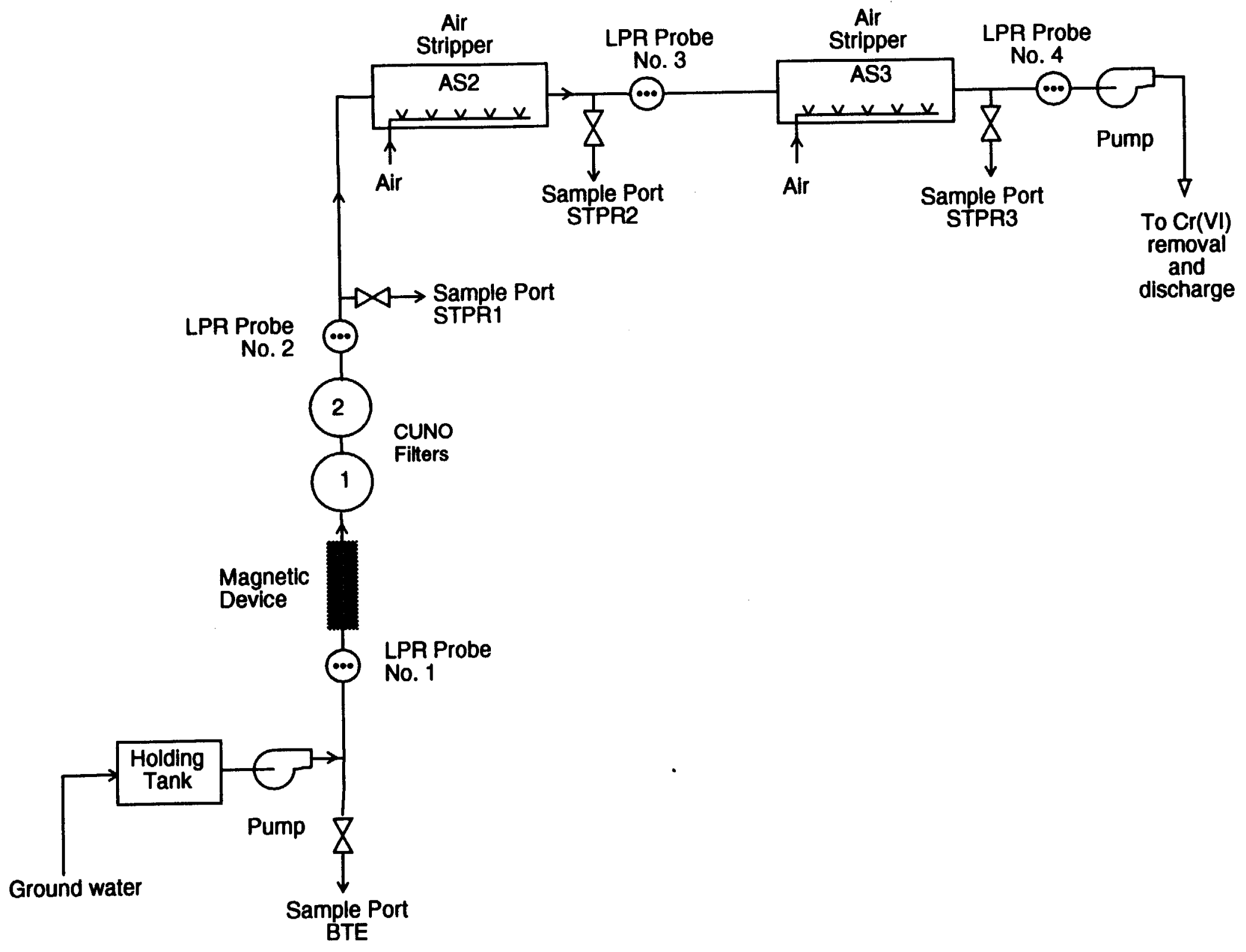

Figure 1. Simplified schematic diagram of flow system at Treatment Facility D. 
As shown in Figure 1, for Test No. LX-122, the magnetic unit (Descal-A-Matic ${ }^{\circledR}$ Model DC-36) was installed in the main water-supply line, after the source of the water from the holding tank and before the two stages of air stripping. This unit was rated for a flow rate of $36 \mathrm{gpm}$; in all of the tests, the water flow rate was maintained at $32.5 \pm 0.2 \mathrm{gpm}$.

The major water parameters (total hardness, total alkalinity, calcium, and total dissolved solids) were measured at the facility using a Hach (Loveland, $\mathrm{CO}$ ) Model CM-1 Corrosion Management Test Kit. Conductivity was measured by means of a YSI Model 33 meter and Model 3310 probe. The $\mathrm{pH}$ was measured using an Orion Model EA $940 \mathrm{pH}$ meter and 81560 probe. Samples for these tests were taken at the locations shown in Figure 1. Samples of the untreated ground water were also analyzed for general water chemistry by California Laboratory Services, Inc. (Rancho Cordova, CA). The VOCs were also measured during the tests. Volatile organic carbon concentrations were not affected by the antiscaling treatments.

Coupons for the primary measurement of scale accumulation consisted of $10-\mathrm{cm}$ circles or squares cut from Type 304 or 316 steel screen. These were cleaned with acetone, weighed to the nearest $0.1 \mathrm{mg}$, and suspended with stainless steel wires in the air-stripper chambers.

The LPR measurements were performed with a Cortest (Willoughby, $\mathrm{OH}$ ) Model IN-7500 meter, and type PR-515GS, stainless-steel probes fitted with Type 1018 mild steel electrodes. The instrument was set up to measure the corrosion rates anodically on a 5-min time cycle. The instrument was calibrated before every series of measurements using the Cortest $10 \mathrm{mpy}$ (mils/year, 0.001-in./year) "meter prover" resistor, which was supplied with the instrument. The steel electrodes were cleaned with acetone, weighed, and kept in a desiccator before installation of the probes in the treatment system. As shown in Figure 1, LPR probes were installed in four locations in the treatment system: (1) just after the main water supply pump, (2) after the magnetic device (when installed) and the CUNO filters, (3) between air strippers AS2 and AS3, and (4) after air stripper AS3.

A good visual indicator of the formation of scale during the tests was the appearance of the polyacrylate windows on the air stripper tanks. These windows became frosty and then opaque, when scaling was pronounced. The scale deposited on these windows was used for the analysis of its crystal structure by $x$-ray diffraction. This was done by scraping a small amount of the scale as a powder onto a microscope slide, and then analyzing it by means of a computer-controlled, Rigaku, wide-anglegoniometer, $x$-ray instrument.

\section{Results and Discussion}

\section{General Water Chemistry}

A summary of the major characteristics of the water that was used in this study is presented in Table 1. The following elements were also measured, but were not detected at or above the reporting limits: $\mathrm{Al}, \mathrm{Cu}, \mathrm{Fe}, \mathrm{Mg}, \mathrm{Ni}, \mathrm{P}$, and $\mathrm{Zn}$. 
Table 1. Major water characteristics of the influent water processed in the scaling tests.

Analyte

$\mathrm{pH}$

Specific Conductance

Total Dissolved Solids

Hardness, as $\mathrm{CaCO}_{3}$

Total Alkalinity, as $\mathrm{CaCO}_{3}$

Bicarbonate Alkalinity, as $\mathrm{CaCO}_{3}$

Sodium

Potassium

Calcium

Magnesium

Chloride

Sulfate

Fluoride

Nitrate, as $\mathrm{NO}_{3}$

Nitrite, as $\mathrm{NO}_{2}^{-}$

\section{Concentration, $\mathrm{mg} / \mathrm{L}$}

$7.1^{\mathrm{a}}$
$1100^{\mathrm{b}}$
750
440
310
310
110
1.7
120
38
210
53
0.66
34
$<2.5$

a pH units

${ }^{b} \mu S$

Water Chemistry During the Tests

The three tests, LX-116 - the baseline test, during which there was no treatment of water for scaling; LX-128 - during which the water was treated with the JP-7 polyphosphate additive; and LX-122 - when the Descal-A-Matic ${ }^{\circledR}$ magnetic device was in place, were carried out for, respectively, 16, 18, and 13 days. Table 2 summarizes the results of the measurements of the principal water parameters at several points in the flow system during the three tests. The $\mathrm{pH}$, total alkalinity, and conductivity data are from measurements made at the facility by LLNL personnel; the other measurements were conducted by California Laboratory Services. Except during Test LX-128, measurements of these parameters were made several times; the ranges of results are presented when the results during a test differed. The temperature of the waters varied from 19 to $25^{\circ} \mathrm{C}$. 
The data in Table 2 show that the primary effect of the air stripping is to raise the $\mathrm{pH}$ of the water by 1 to $1.5 \mathrm{pH}$ units, presumably because dissolved carbon dioxide is removed. Given the experimental variation of the other parameters, there is no evidence of any other chemical changes in the water as it passed through the system. There was little, if any further increase in the $\mathrm{pH}$ of the water in Air Stripper Tank No. 3. There is also no indication from these data that either the JP-7 additive or the magnetic device had an appreciable effect on the water chemistry. Water chemistry values of LX-128 and -122 were compared to LX-116 using the student $t$ test. No significant difference was found in the water chemistry values of the treated ground water compared to the untreated water.

Table 2. Water chemistry during scaling tests.

\begin{tabular}{|c|c|c|c|c|c|c|c|}
\hline Test Number & $\begin{array}{c}\text { Sample } \\
\text { Port }\end{array}$ & $\mathrm{pH}$ & $\begin{array}{c}\begin{array}{c}\text { Conductivity } \\
(\mu S)\end{array} \\
\end{array}$ & $\begin{array}{l}\mathrm{TDS}^{\mathbf{b}} \\
(\mathrm{mg} / \mathrm{L})\end{array}$ & $\begin{array}{c}\text { Calcium } \\
(\mathbf{m g} / \mathbf{L})\end{array}$ & $\begin{array}{c}\text { Total } \\
\text { Alkalinity } \\
(\mathbf{m g} / \mathbf{L})^{\mathbf{a}} \\
\end{array}$ & $\begin{array}{c}\text { Total } \\
\text { Hardness } \\
(\mathbf{m g} / \mathbf{L})^{2} \\
\end{array}$ \\
\hline LX-116 & BTE & $7.0-7.2$ & 1100 & $770-790$ & $97-120$ & $310-340$ & $380-460$ \\
\hline \multirow[t]{3}{*}{ Baseline } & STPRI & $7.2-7.3$ & 1000 & $750-780$ & $95-120$ & $310-320$ & $370-440$ \\
\hline & STPR2 & $8.1-8.5$ & 1000 & $730-740$ & $95-100$ & $300-360$ & $370-410$ \\
\hline & STPR3 & $8.4-8.6$ & 1000 & $750-800$ & $96-120$ & $310-370$ & $380-450$ \\
\hline LX-128 & BTE & 7.0 & 1200 & 790 & 110 & 330 & 440 \\
\hline JP-7 & STPRI & 7.0 & 00 & 750 & 110 & 320 & 440 \\
\hline \multirow[t]{2}{*}{ Polyphosphate } & STPR2 & 8.3 & 1200 & 790 & 120 & 340 & 460 \\
\hline & STPR3 & 8.3 & 1100 & 780 & 120 & 330 & 460 \\
\hline LX-122 & BTE & 7.3 & $1100-1200$ & $680-840$ & $110-120$ & $310-340$ & $440-460$ \\
\hline Magnetic & STPRI & 7.3-7.4 & 1100 & $750-790$ & $110-120$ & $300-320$ & $440-450$ \\
\hline \multirow[t]{2}{*}{ Device } & STPR2 & 8.3 & 1100 & $700-770$ & $96-100$ & 270 & $400-430$ \\
\hline & STPR3 & $8.5-8.6$ & 1100 & $750-790$ & $110-120$ & 320 & $440-470$ \\
\hline
\end{tabular}

aAs $\mathrm{CaCO}_{3}$

bTDS- total dissolved solids 
Results of Coupon Tests

Two coupons made from stainless-steel screen were suspended in each of the two air stripper tanks to measure the accumulation of scale gravimetrically; Table 3 presents the results of this experiment. The scale that accumulated on these coupons

Table 3. Changes in weight of the stainless-steel screen coupons.

\begin{tabular}{|c|c|c|c|c|c|}
\hline $\begin{array}{c}\text { Test } \\
\text { Number } \\
\end{array}$ & $\begin{array}{c}\text { Air } \\
\text { Stripper } \\
\text { Number }\end{array}$ & $\begin{array}{c}\text { Type of } \\
\text { Stainless } \\
\text { Steel }\end{array}$ & $\begin{array}{l}\text { Coupon } \\
\text { Weight } \\
\text { Gain (g) }\end{array}$ & $\begin{array}{c}\text { Duration of } \\
\text { Test (days) }\end{array}$ & $\begin{array}{c}\text { Scale } \\
\text { Build-up } \\
\text { Rate (g/day) }\end{array}$ \\
\hline LX-116 & 2 & 304 & 10.1261 & 16 & 0.63 \\
\hline Baseline & 3 & 304 & 3.3153 & 7 & 0.56 \\
\hline & $\begin{array}{l}2 \\
3\end{array}$ & $\begin{array}{l}316 \\
316\end{array}$ & $\begin{array}{l}3.9188 \\
2.1859\end{array}$ & $\begin{array}{l}16 \\
7\end{array}$ & $\begin{array}{l}0.21 \\
0.31\end{array}$ \\
\hline $\begin{array}{l}\text { LX-128 } \\
\text { JP-7 }\end{array}$ & $\begin{array}{l}2 \\
3\end{array}$ & $\begin{array}{l}304 \\
304\end{array}$ & $\begin{array}{l}-0.0218 \\
-0.0223\end{array}$ & $\begin{array}{l}18 \\
18\end{array}$ & $\begin{array}{l}0 \\
0\end{array}$ \\
\hline & $\begin{array}{l}2 \\
3\end{array}$ & $\begin{array}{l}316 \\
316\end{array}$ & $\begin{array}{l}-0.0074 \\
0\end{array}$ & $\begin{array}{l}18 \\
18\end{array}$ & $\begin{array}{l}0 \\
0\end{array}$ \\
\hline $\begin{array}{l}\text { LX-122 } \\
\text { Magnetic }\end{array}$ & $\begin{array}{l}2 \\
3\end{array}$ & $\begin{array}{l}304 \\
304\end{array}$ & $\begin{array}{r}12.6841 \\
6.9897\end{array}$ & $\begin{array}{l}13 \\
13\end{array}$ & $\begin{array}{l}0.98 \\
0.54\end{array}$ \\
\hline & $\begin{array}{l}2 \\
3\end{array}$ & $\begin{array}{l}316 \\
316\end{array}$ & $\begin{array}{l}9.5339 \\
5.6342\end{array}$ & $\begin{array}{l}13 \\
13\end{array}$ & $\begin{array}{l}0.73 \\
0.43\end{array}$ \\
\hline
\end{tabular}

was a milky-white, crystalline-appearing deposit, known from previous work to be primarily calcium carbonate. Each coupon at the start of the test weighed $15-20 \mathrm{~g}$. Use of these coupons quantitatively measured the combined effects of corrosion and scaling, and these data show some interesting effects. First, it appears that the rate of scaling, if any, was about the same in both air stripper tanks. This result, and the chemical analyses discussed above, probably means that the major change in water chemistry occurs in Air Stripper Number 2 and that a further change in Number 3 is minimal. Secondly, in the baseline test, LX-116, scale build-up on the Type 316 stainless steel coupon was less than that on the Type 304 coupon. This reflects a general finding that in short-term tests like these, surfaces that are more resistant to corrosion (such as 316 vs. 304) also tend to accumulate scale at a lower rate. Third, as shown in the results of 
Test LX-128, the JP-7 additive very effectively retards scale deposition, thus these data reflect only the rates of corrosion, with Type 316 steel again being more resistant. Finally, and most important in the context of this project, these data show that the magnetic device not only did not inhibit scale formation, it appeared to enhance it. In fact, as will be discussed further below, Test LX-122 had to be terminated at 13 days, a shorter duration than the other tests, because the system operational characteristics also indicated increased, detrimental scale formation.

The LPR electrodes were also used as weight gain/loss coupons, and in general exhibit the same major trends as those of the stainless-steel screens. These data are presented in Table 4. Each probe has three electrodes, and the results for each set of

Table 4. Changes in weight of the electrodes on the LPR probes. (See Figure 1 for probe position and Table 3 for test duration.)

\begin{tabular}{llc}
$\begin{array}{c}\text { Test } \\
\text { Number }\end{array}$ & $\begin{array}{c}\text { Probe } \\
\text { Number }\end{array}$ & $\begin{array}{c}\text { Scale Build-up Rate } \\
\text { (mg/day) }\end{array}$ \\
\hline LX-116 & 1 & 1.2 \\
Baseline & 2 & -0.1 \\
& 3 & 19.1 \\
& 4 & 2.9 \\
LX-128 & 1 & \\
JP-7 & 2 & 1.2 \\
Polyphosphate & 3 & -0.3 \\
& 4 & 1.6 \\
LX-122 & 1 & 1.3 \\
Magnetic & 2 & 0.7 \\
Device & 3 & 0.4 \\
& 4 & 21.2 \\
& & 5.1 \\
\hline
\end{tabular}

three were averaged to obtain a mean rate of scale build-up. In this case, since the metal is the less-resistant, Type 1018 mild steel, there is expected to be more corrosion. (Note that the absolute rates of scale build-up here cannot be compared with those of Table 3 , because the surface areas of the specimens are different.)

Probe numbers 1 and 2 were positioned ahead of the air strippers, thus in all three tests they showed very little weight change due to either scaling or corrosion. In LX-122 and LX-128, there was a slight weight loss at No. 2. In Test LX-128, the effectiveness of the JP-7 is shown by the low weight changes in the electrodes on the probes at the downstream positions after the air stripping. Comparing the results for probe Nos. 3 and 4 in Tests LX-116 and LX-122, it can again be seen that the magnetic device had no beneficial effect on the scaling rate. The most weight gain was always found for probe No. 3, which was positioned between the two stages of air stripping. The electrodes at this position were found to be covered completely with a white, 
powdery substance similar in appearance to that found on the screen coupons. The surfaces of the other probe electrodes exhibited both scale and rust-colored corrosion products.

\section{Linear Polarization Resistance (LPR) Measurements}

As noted above, the linear polarization resistance (LPR) measurements were performed because it was thought that these measurements might provide a "realtime," instead of an after-the-fact, indication of the scaling rates and the effects of the water treatment. In scaling environments, the apparent corrosion rate as found by the LPR measurement will be inversely proportional to the amount of impervious scale that has accumulated on the electrodes.

In the present experiments, the LPR measurements at each probe were performed at the end of each day's facility operation. Figures 2 and 3 are plots of the data obtained. Measurement of the calibrating resistor during each day's series showed that the standard deviation of the measurement at 10 mpy was $\sim 0.3 \mathrm{mpy}$.

For each of these probes, and during all three tests, there was a period of several days when the apparent corrosion rate decreased rapidly. This behavior is typical for all aqueous environments, especially when the corrosion rate is low $(<10 \mathrm{mpy})$, and is due to the initial equilibration of the electrode surfaces. On first exposure of the electrodes, a microscopic film of both a partly soluble corrosion product (such as iron oxide) and a scale deposit (such as $\mathrm{CaCO}_{3}$ ) may form, which more rapidly decreases the apparent corrosion rate. The apparent corrosion rate then tends to level off as both of these films build up. In these tests, it appears that at least 5 days are required to obtain a meaningful indication of the corrosion rates from the LPR data. However, in all of the tests, the apparent corrosion rate was still slowly decreasing when the tests were terminated, and final equilibrium may not be reached until after $\sim 15$ days.

Several significant features can be seen in the LPR data. First of all, as can be seen in the data for the test without water treatment (Figs. 2 and 3), the apparent "equilibrium" corrosion rate of the electrodes was progressively lower in going from Probe 1 to Probe 4 . This is expected even in a non-scaling environment, because, as the $\mathrm{pH}$ of the water increases as it passes through the facility, the actual corrosion rate of the steel should trend to lower values. The additional effect of the deposition of the $\mathrm{CaCO}_{3}$ scale, if it is evident, would be superimposed on the effect of corrosion.

As can be seen in Figure 2, which depicts the LPR data for the water prior to the air stripping, there is very little effect, if any, of the type of water treatment on the LPR results. The effects of the water treatment on the apparent corrosion rates are more clearly differentiated after the water has undergone air stripping, especially in the data for LPR Probe No. 3, which was located between the two stages of air stripping. As can be seen in Fig. 3 (top curves), after a few days, the indicated corrosion rates were generally the highest for the JP-7 treated water, presumably because there is less $\mathrm{CaCO}_{3}$ scaling under this condition. For the untreated water, and at intermediate times, the apparent corrosion rates were lower for the untreated water, probably because of the 

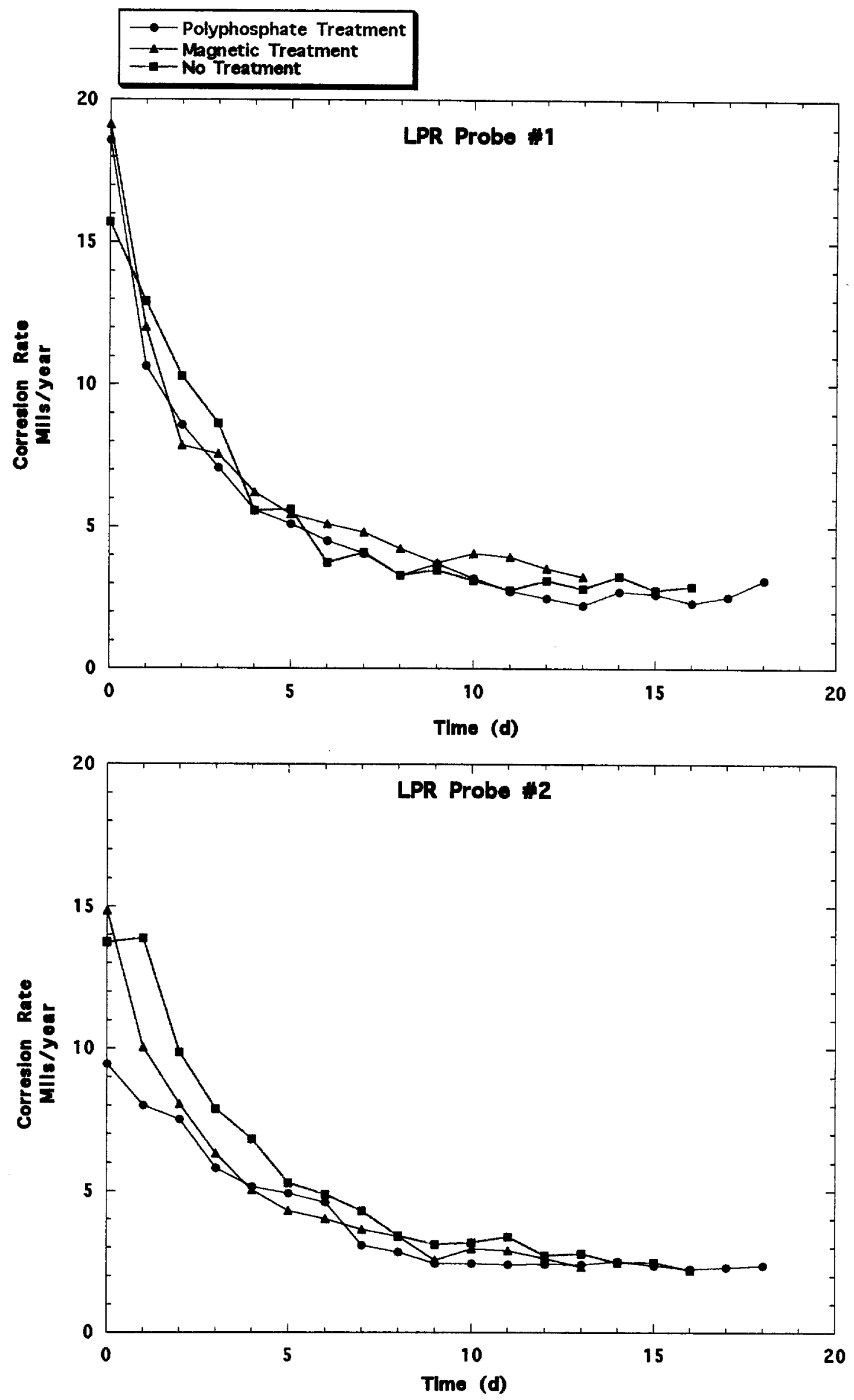

Figure 2. Linear polarization resistance measurements at Probe numbers 1 and 2. 

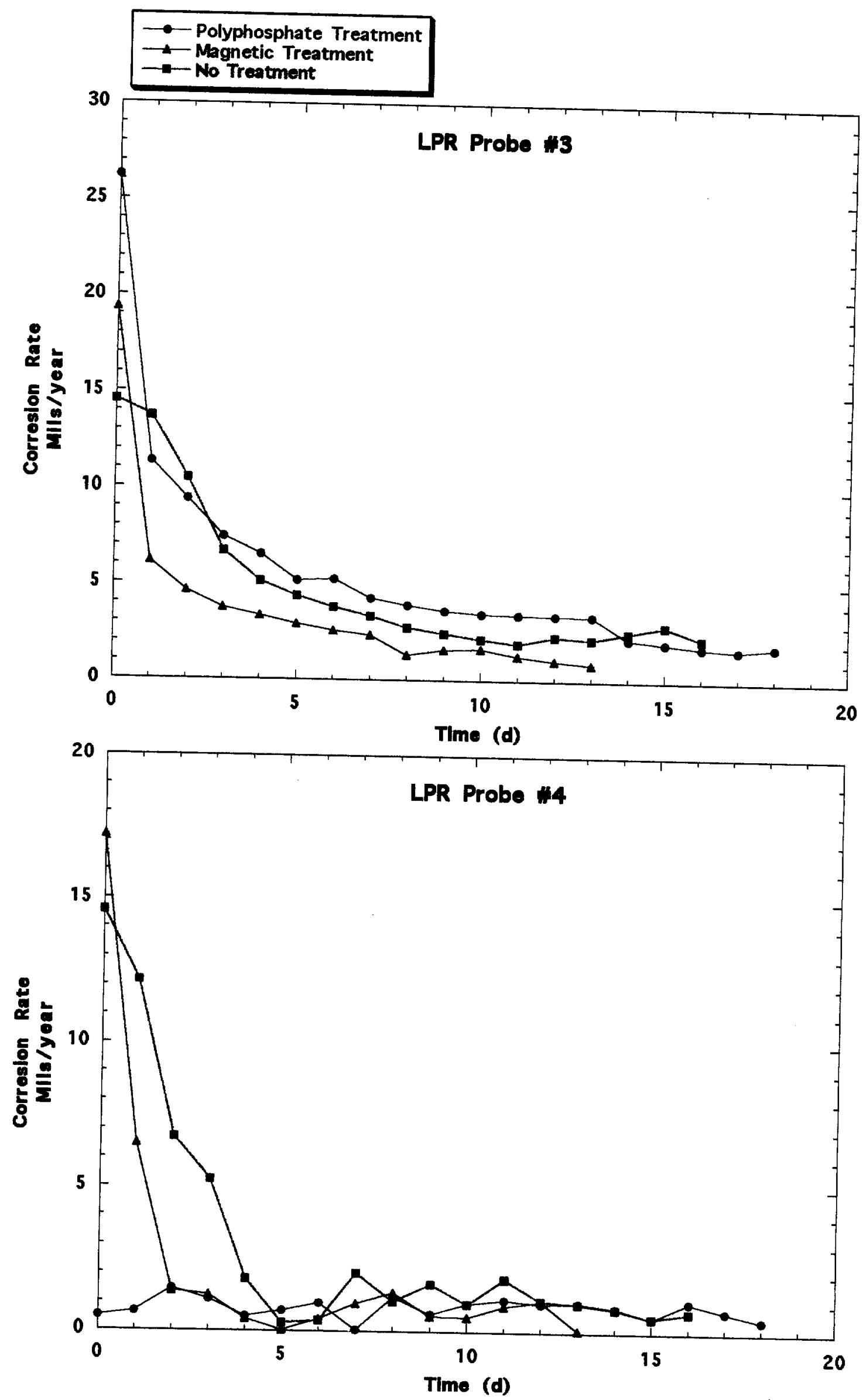

Figure 3. Linear polarization resistance measurements at Probe numbers 3 and 4. 
faster build-up of the $\mathrm{CaCO}_{3}$ scale. If the magnetic treatment (or any anti-scale trea tment) were effective in retarding scale formation, the apparent LPR corrosion rate should always be higher than that observed in the absence of treatment. The contrary effect was observed: the corrosion rates indicated by Probe No. 3 were lower when the magnetic device was in place. This observation of even more scaling with the magnetic treatment is in agreement with the coupon results.

The reason for the initially low LPR values for Probe No. 4 in the polyphosphate treated water (Fig. 3, bottom curves) is unknown. However, there was an indication that the orientation of Probe No. 4 in the flow stream was not completely satisfactory. It was observed that the deposition of scale was uneven on the electrodes of Probe No. 4.

\section{Mineralogical Analysis of the Scale}

It was also of interest to identify the crystal structure of the $\mathrm{CaCO}_{3}$ scale that formed during these tests, and to determine whether the magnetic treatment had any effect on it. It was previously determined that this scale was ordinarily deposited as calcite, but according to the sales representative of the Descal-A-Matic ${ }^{\circledR}$ company (McClellan, 1996), the magnetic field may have the effect of causing the scale to deposit as aragonite, and that this might also be beneficial, because aragonite would be softer, and less adherent than calcite.

After Tests LX-116 and LX-122, powdered samples were scraped off the polyacrylate windows in air-stripper tank No. 2, and analyzed by $x$-ray diffraction. Figure 4 shows the diffraction pattern for the scale formed during Test LX-122, when the magnetic device was in place, together with the reference patterns for calcite and aragonite. Figure 5 compares patterns for samples from both LX-122 and the baseline Test LX-116. In both of the samples, the major component of the scale is clearly calcite, with no evidence of aragonite (or valerite, another possible crystal form). It can be seen in Figure 5 that there are some differences in the two patterns (i. e., the number of diffraction lines and the line intensities), but these differences are not significant in the identification.

Because calcite is the thermodynamically stable crystal form of $\mathrm{CaCO}_{3}$, there is the possibility that, after precipitation and deposition in an experiment, the other crystal forms such as aragonite may transform to calcite before the samples can be analyzed. However, the rate of such a transformation is known to be very slow at ordinary temperatures, in either aqueous environments or in the dry state. For example, $\mathrm{CaCO}_{3}$ coral in the oceans deposits as aragonite; aragonite, rather than calcite, is found in dry geologic beds; and aragonite can be examined in this form in the laboratory without transformation (Veeh and Burnett, 1982).

\section{Facility Operational Characteristics}

An operational characteristic of the treatment facility equipment that became a good indicator of the extent of scaling was the back pressure on the diffusers in the air stripper tanks. These diffusers consist of sections of pipe that are drilled with multiple 
small holes, through which the air flows into the water as the water is pumped through the tanks. The formation of scale in and around these holes restricts the openings and creates increasing back pressures that were indicated on gauges and recorded during the treatment tests.

Figure 6 illustrates the variation of the air-stripper diffuser back pressures during the tests. With the addition of JP-7 to the water (in Test LX-128), there was essentially no change in the back pressure during this test. With no anti-scale water treatment (Test LX-116), the pressure started to increase after about 8-day's running. In the case of Test LX-122, with the magnetic device in place, the pressure began to increase after only 4 days, and the test was terminated after 13 days because the pressure had reached an intolerable level.

Although not dramatic, it appears, from the variety of tests that were performed that the Descal-A-Matic ${ }^{\circledR}$ device increased the scaling tendency of the water when its $\mathrm{pH}$ was raised by the air stripping. We cannot provide an exact mechanism for this effect, but one reason may be the fact that insertion of the device into the fluid stream introduced a rather large, additional pressure drop. When the device was first installed the system input pressure required to achieve the target $32.5 \mathrm{gpm}$ flow rate increased from $\sim 5$ to $\sim 16 \mathrm{psi}$. After the tests, the differential pressure drop directly across the magnetic unit was measured by means of calibrated gauges and found to be

11 psi. This additional pressure drop at the system inlet, prior to air stripping, may in some way slightly upset the chemical equilibria in the water. 


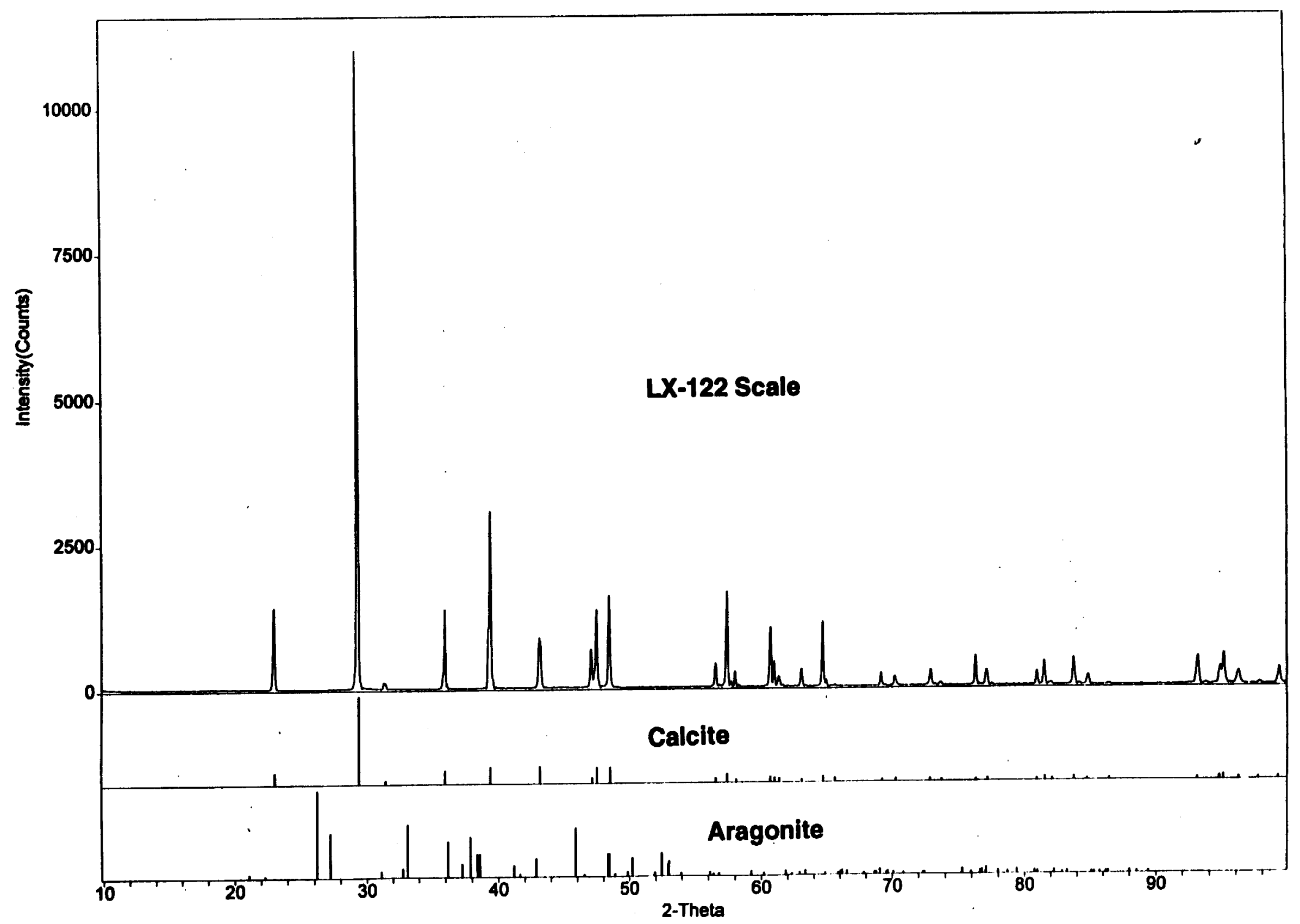

Figure 4. Diffraction pattern of scale formed during Test $L X-122$ with the magnetic unit, together with reference patterns for calcite and aragonite. 


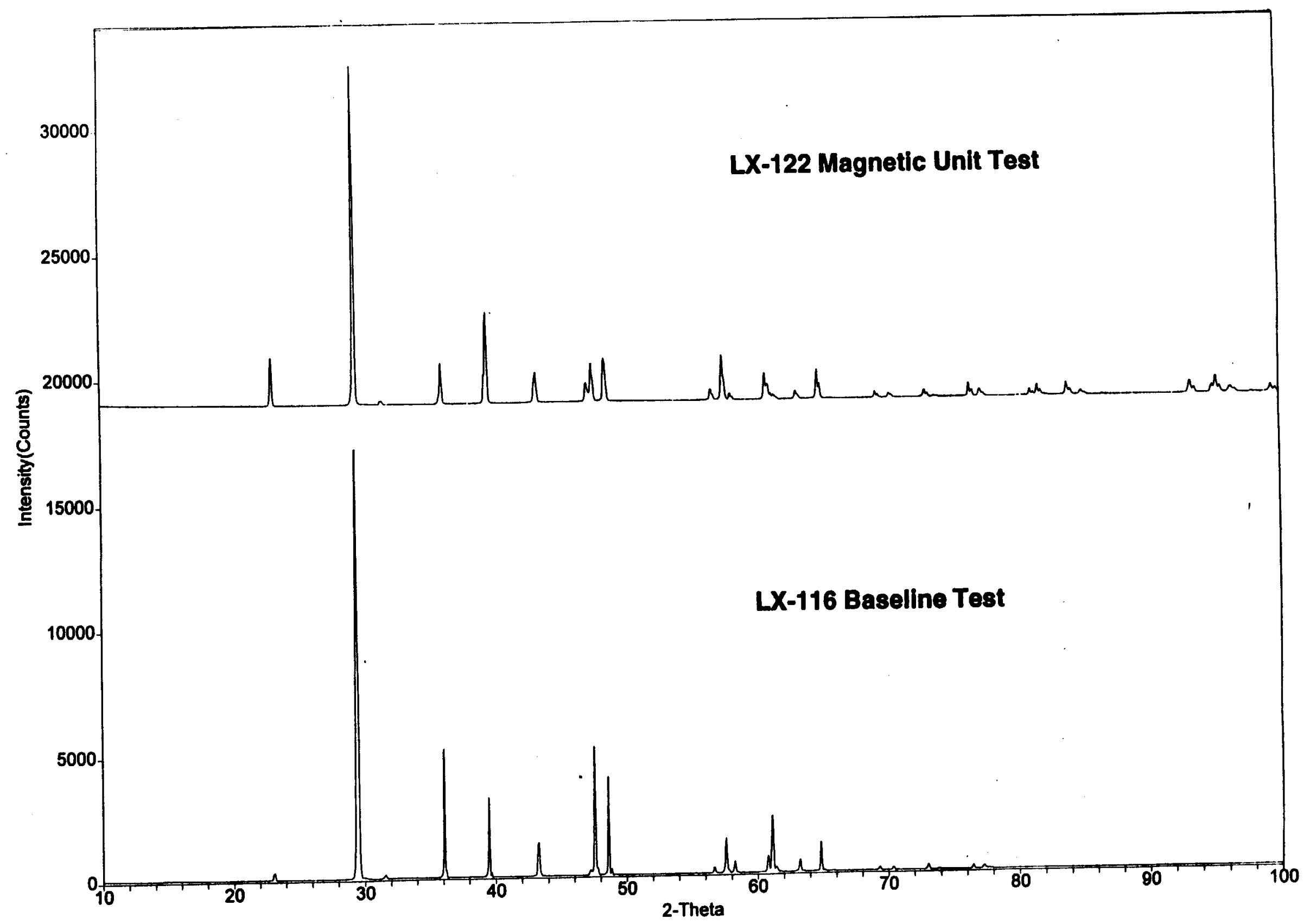

Figure 5. Diffraction patterns of scale formed during the baseline test $L X-116$, and the magnetic unit test, LX-122. 


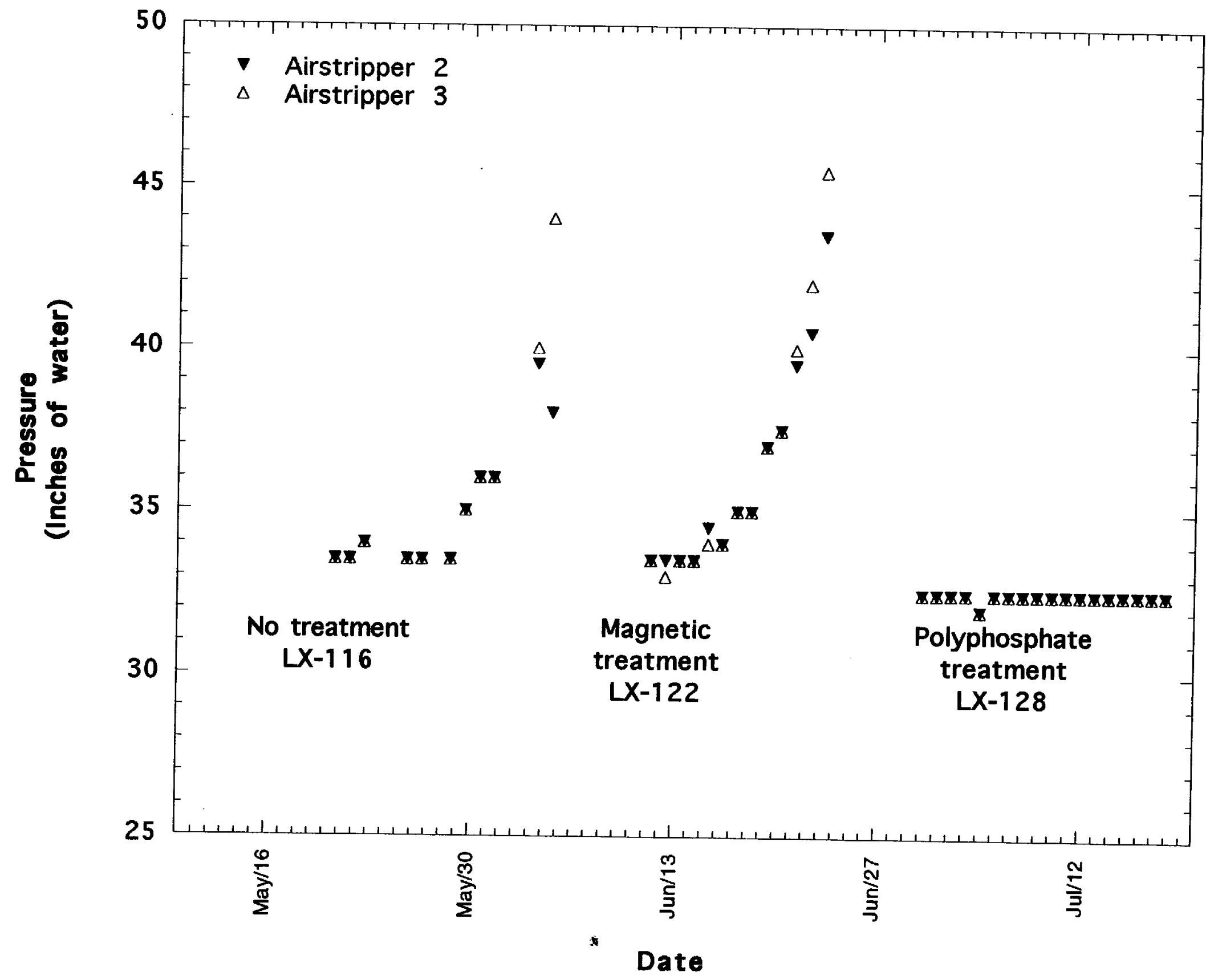

Figure 6. Back pressure at the air diffusers. 


\section{Conclusions}

The Model DC-36 Descal-A-Matic ${ }^{\circledR}$ magnetic device, as evaluated in this investigation, was not useful for scale control at Treatment Facility D. However, there are many variables in the general approach of magnetic, antiscale water treatment that we did not examine. Sizing and positioning of the device in the flow stream, as well as the use of different types of magnetic equipment, might be more successful. At present, testing of magnetic devices in general appears to be strictly empirical. Advances in the understanding of the exact mechanism of magnetic anti-scale control, where it is successful, would certainly stimulate and facilitate further investigation.

The methodologies and results of this study constitute a good format and a set of baseline data that could be used to test other candidate scale-control techniques at the various local treatment facilities. The weight-change coupons and the diffuser pressure measurements were the best diagnostics for detecting and quantifying the scale formation. The linear polarization resistance (LPR) technique was not as sensitive as expected in indicating differences in scaling rates, but in one probe location, the LPR measurements did clearly exhibit the expected effects. As an indicator of corrosion rates, LPR measurements should also be useful in screening construction materials for future installations.

\section{Future Work}

Because our objective of inhibiting scale formation by the use of the magnetic device was not realized, we propose several approaches to maintain the ground water at a neutral $\mathrm{pH}$ after air stripping. One method is to add $\mathrm{CO}_{2(\mathrm{~g})}$ to the compressed air used for VOC removal. An earlier attempt at $\mathrm{pH}$ adjustment by carbon dioxide injection prior to air stripping was ineffective due to the loss of the $\mathrm{CO}_{2}(\mathrm{~g})$ in the process. An alternative method is to introduce $\mathrm{CO}_{2}(\mathrm{~g})$ prior to air stripping using a gas/liquid membrane contactor. The third method is to add hydrochloric acid to the ground water prior to air stripping.

The $\mathrm{pH}$ of the water before air stripping is $\sim 7$, and after air stripping is $\sim 8$. Our objective is to add sufficient $\mathrm{CO}_{2(\mathrm{~g})}$ or $\mathrm{HCl}$ solution to the water prior to air stripping to cause the ground water to return to it's original $\mathrm{pH}$ value, thus retarding or eliminating scale formation. Other common organic antiscalants may also be evaluated.

We need to test the ground water for an exact measurement of the $\mathrm{HCl}$ titer however, based on existing data, we estimate that $\sim 2 \mathrm{meq} / \mathrm{L}$ would be required. If $\mathrm{pH}$ adjustment with acid is successful it could result in a cost savings compared to the use of polyphosphate additives. In addition, $\mathrm{pH}$ adjustment with $\mathrm{HCl}$ or $\mathrm{CO}_{2(\mathrm{~g}) \text {, as }}$ described above, would eliminate the $\mathrm{CO}_{2}(\mathrm{~g})$ injection necessary to adjust the $\mathrm{pH}$ of the effluent ground water back to 7 , which our current process requires. This would result in increased cost savings. 


\section{Key Results}

- The air stripping process increases the $\mathrm{pH}$ of the ground water at Treatment Facility D from 7.0-7.5 to 8.0-9.0.

- The $\mathrm{pH}$ change results in a shift in the carbonic acid equilibria in the water and increases the tendency toward precipitation of $\mathrm{CaCO}_{3}$ scale on the surfaces of the equipment.

- The scale was determined by $\mathrm{x}$-ray diffraction to be the calcite form of $\mathrm{CaCO}_{3}$.

- Several useful techniques were developed for measuring the rates of scale formation in the treatment system, which can be used to compare scale abatement techniques.

- The results of the Linear Polarization Resistance (LPR) measurement technique agreed well with those of the weight-gain coupons, and provided a real-time indication of scaling rates.

- Less scale buildup occurred on the Type 316 stainless-steel coupons than on the Type 304 coupons, and the Type 316 steel was more resistant to corrosion.

- The polyphosphate antiscalant decreased the rate of calcium carbonate scale formation in these experiments virtually to zero .

- The Descal-A-Matic ${ }^{\circledR}$ magnetic device did not inhibit scale formation, and in fact, enhanced it slightly.

\section{Acknowledgments}

The x-ray diffraction analyses of the scale samples were performed by D. F. Del Giudice of LLNL's Chemistry \& Materials Science Department. We are also grateful to Kevin Knauss of LLNL's Geosciences and Environmental Technologies Program for information on the possible conversion of the crystal forms of calcium carbonate. Scott Kawaguchi assisted in the operation of Treatment Facility D during the scale control tests. 


\section{References}

Baker, J. S., and S. J. Judd, Wat. Res., 30, 247 (1996).

Chem. Eng. News, June 24, 1996, p. 96.

The Economist, March 2, 1996, p. 74.

Mansfeld. F., "The Polarization Resistance Technique for Measuring Corrosion

Currents," in Advances in Corrosion Science \& Technology, M. G. Fontana and R. W. Staehle, Eds., Plenum Press, New York, 1976, Vol. 6, Chapter 3.

McClellan, D. A., MC 2 Resource Management Co., Hilmar, CA, personal communication, 1996.

Veeh, H. H., and W. C. Burnett, "Carbonate and Phosphate Sediments," in Uranium Series Disequilibrium: Applications to Environmental Problems, M. Ivanovich and R. S. Harmon, Clarendon Press, Oxford, 1982, Chapter 17. 


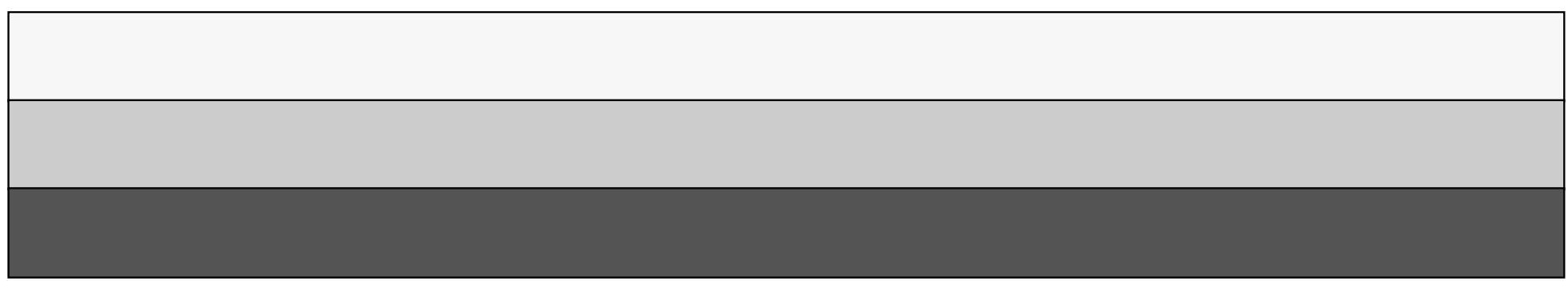

